\title{
O vocabulário da habilidade e da competência: algumas considerações neopragmáticas
}

\author{
Pedro Fernando Bendassolli ${ }^{28}$
}

\begin{abstract}
O objetivo deste artigo é apresentar e discutir alguns dos principais elementos que compõem o chamado vocabulário da habilidade e da competência. A partir de um resgate teórico de alguns conceitos elaborados pela filosofia neopragmática da linguagem, é proposto que tal vocabulário é caracterizado como um complexo discursivo articulado pelas noções de personalidade, de ação individual, de performance e pela noção de learning society, ou seja, da idéia de uma sociedade voltada para o conhecimento e aprendizagem constantes. $O$ artigo desenvolve ainda o argumento de que o vocabulário da habilidade e da competência institui determinadas formas de vida que passam, em função da sua repetição e reiteração, a figurar como modalidades quase que inquestionáveis e naturais dos mecanismos de formação da subjetividade numa época em que as grandes narrativas identitárias perdem sua consistência, incluindo, entre outras, a perda das narrativas de classe, das narrativas coletivas articuladas em torno das politicas do Estado de Bem-Estar Social e a corrosão da sociedade do trabalho (o fim do pleno emprego). Palavras-Chave: neopragmatismo, trabalho, subjetividade, discurso.
\end{abstract}

\begin{abstract}
$\mathrm{M}$ eu amigo, há algumas regrinhas que você, que quer subir na vida, tem de saber na ponta da língua. Primeira, nunca pare de estudar, você tem de ampliar cada vez mais todos os seus conhecimentos, em todas as esferas de sua vida. Estude, procure sempre se manter atualizado, informado, por dentro de tudo o que se passa ao seu redor, na família, no trabalho, no grupo de amigos e até na feirinha de bairro em que vai todo domingo. Segunda regra: é uma decorrência da anterior, pois se você estudar sempre, se reciclar sempre, estará habilitado para concorrer no mercado, para se diferenciar de seus adversários ou oponentes; você não precisará sequer se filiar a uma empresa, pois será ela que ganhará em tê-lo como parceiro. Resumindo, então: faça a diferença, aprenda, seja esperto e, acima de tudo, do it by yourself.
\end{abstract}

O excerto acima bem poderia fazer parte da ficção, sem vínculo nenhum com a realidade. Mas não. O vocabulário aí empregado, as regras semânticas nele veiculadas, já nos são tão familiares, tão comuns e naturais, que não podemos duvidar delas, nem muito menos nos dar conta de como se formaram. O que parece ser visível são seus efeitos inquestionavelmente reais, presentes nas cenas do dia-a-dia de boa parte das pessoas, estejam onde estiverem. O curioso, nisso tudo, é o menos notado: como é que apreendemos a intenção de sentenças como as colocadas acima? Ou seja, por que elas fazem sentido entre nós? Alguns podem dizer que simplesmente as aprendemos. De tanto ouvi-las, escrevê-las, vê-las escritas, comentadas e faladas acabamos por, intuitivamente, reproduzi-las em nosso próprio repertório lingüístico e comportamental. E isso não é pouco. Muito se fez a partir daí. Mas, se prestarmos bastante atenção, poderemos ver que muitos dos termos empregados são tão genéricos que podem, no limite, ser aplicados a quaisquer situações, a quaisquer propósitos, sejam eles na empresa ou não. De onde proviria esta abrangência de escopo?

Genéricos ou não, eles "funcionam". Funcionam, primeiro, porque são "necessários". Afinal, quem ousaria discordar de que estamos num momento onde a aquisição e

${ }^{28}$ Mestrando em Psicologia Social do Instituto de Psicologia da Universidade de São Paulo. Orientador: Sigmar Malvezzi. 
aperfeiçoamento de habilidades são simplesmente fundamentais? Argumento: se eu não estudar, estou fora; se eu não for competente, estarei colocado na linha do trem; se eu não apreender as contingências ao meu redor, e transformá-las adequadamente, serei passado para trás. As exigências são claras e têm endereço certo. Mas, tenho de colocar uma questão: como aqueles termos que apresentei acima puderam se revestir com esse caráter de necessidade? Ora, poder-se-ia argumentar, novamente, que são necessários porque a "realidade" assim o exige. Mas, isso seria uma redundância que pouco nos diz. Então poderíamos pensar que esses termos são assim importantes porque o mercado os demanda, a economia os incentiva, o "meio" os criou etc. Suponhamos, entretanto, outro caminho.

Se as "evidências" da "realidade" não satisfazem inteiramente as condições para uma boa explicação sobre a nossa aceitação do vocabulário da habilidade e competência (tal como foi sinteticamente exemplificado no exemplo de partida), onde então poderíamos encontrá-la? Tenho uma hipótese: tal vocabulário tornou-se plausível simplesmente pelo fato de que ele atende a fortes motivos pragmáticos. Colocando de outra forma: se admitirmos que a linguagem não é meramente um "representante" da "realidade", e se admitirmos que as palavras são ferramentas das quais dispomos para responder ao mundo, então não seria distante admitir que a linguagem é uma forma de vida, expressa em vários jogos de linguagem, em várias e distintas formas de interagir com os estímulos do mundo em que vivemos. "Mundo", aqui, significa: as pessoas com as quais se convive; as situaçõesdesafio com as quais se é confrontado; todos os objetos que aprendemos a descrever e a relacionar com outros objetos. Então, podemos pensar: se termos como "aprendizagem constante"; "aquisição de competências e conhecimento"; "competitividade"; "enfrentamento do mercado de trabalho", entre tantos outros, são plausíveis, ou seja, são "verdadeiros" (no sentido de que os autorizamos como regras ou normas de comportamentos induzidos e valorizados, seja como "necessários", "reais" ou "corretos"), é porque eles visam a certos propósitos, instituem uma dada forma de vida, articulam um certo jogo de linguagem - e tudo isso tem implicações imediatas sobre como nos comportamos, sobre como admitimos os outros, sobre como achamos que deve ser nossa vida e nossas relações mútuas. Enfim, trazendo para o caso aqui, esse jogo de linguagem é plausível porque fomos instruídos, e fomos treinados, a reagir a ele na qualidade de complexos discursivos, cuja validade pragmática (ou prática) até então se provou "eficaz", pelo menos dentro de um determinado parâmetro social e subjetivo e de determinadas formas de vida. No caso, dentro do parâmetro do chamado "mercado de trabalho", da "economia" e, principalmente, dentro das chamadas "teorias de gerenciamento de recursos humanos".

Neste pequeno texto vou tentar responder a três indagações. Primeira: em que contexto as ditas "habilidades" passaram a fazer sentido para nós, tornando-se um aspecto privilegiado da pauta de discussões do Gerenciamento de Recursos Humanos? Segunda: como o vocabulário que enuncia ou expressa tais habilidades passou a constituir formas de vida, ou jogos de linguagem, de interesse comum? Terceira: quais as relações desse vocabulário com a produção da subjetividade? Essas três indagações talvez pareçam mais ambiciosas do que esse texto pode, a princípio, suportar. Para evitar esse risco, vou adotar aqui um tom próximo ao de uma crônica, e a preocupação central estará orientada para o levantamento de questões - mais do que para demonstrações sistemáticas e exaustivas de respostas. Por essa razão, será feita uma revisão bastante precisa e específica da literatura, selecionando aquelas contribuições teóricas mais diretamente envolvidas com a discussão que se segue. 


\section{Um start neopragmático}

Quando falamos em habilidades - skills - pensamos em que exatamente? Seja o que for que pensemos, isso não será feito num vácuo semântico. Para sabermos o que é ou não é uma habilidade, a que exatamente ela visa ou responde, temos de situá-la, falar sobre ela, colocá-la numa trama de termos e num determinado jogo de linguagem. E, além disso, temos de enganchá-la numa determinada teoria de verdade. Esta última significa exatamente: um acordo entre falantes da língua acerca do valor de verdade atribuído à conexão entre um referente e aquilo que ele denomina. Colocando de outra forma: "verdade", aqui, não tem um sentido epistemológico (ou seja, um sentido que arbitraria as condições necessárias para o conhecimento legítimo, para a adequada apreensão do esquema sujeito-objeto), mas sim um sentido semântico: podemos apenas dizer o que é verdade como sendo efeito de interpretação, isto é, não há nada no conceito de verdade senão um intérprete olhando uma atividade lingüística como causalmente conectada com alguma coisa do mundo. Isso significa que o termo "verdade" não pode explicar como viemos a constituir nossas crenças sobre o mundo; simplesmente diz como é que passamos a chamar certas crenças de verdadeiras. Mas o termo "verdade" não é inócuo: ele resulta de acordo entre pessoas. Nesse contexto, dizer que algo é verdadeiro implica numa concordância de propósitos e na disposição para se aceitar o comportamento lingüístico do outro como semelhante àquele de quem fala. A "verdade", no sentido que usamos aqui, é um termo de aprovação (Costa, 1992, 1994, 1995, 1998, 1999; Davidson, 1985; Ghiraldelli Jr., 1997, 1998, 1999, 2000a, 2000b; Rorty, 1979, 1991, 1995, 1999).

Mas, apesar de restringir assim o conceito de verdade, deslocando-o da epistemologia (do Cogito) para a semântica (para a linguagem), temos de dar um passo à frente. Se a discussão semântica da verdade não pode fazer nada além de nos apontar que esse/aquele termo é verdadeiro, em função de certos propósitos, acordos e circunstâncias, ele também não pode nos dizer por que viemos a adotar certas crenças, ou certas palavras, para designar certas coisas do mundo. Para tanto é preciso um outro ponto: a história das justificações (Costa, 1995). Tentando trocar em miúdos: uma vez no campo de tal história, temos de nos preocupar com a seguinte questão: como é que elegemos certos termos para designar certas coisas? Isto é, trata-se de justificar, ou de tornar plausível, o que faz - ou fez - com que possamos admitir determinadas crenças como verdadeiras, tais como as crenças embutidas nos discursos que tratam de competência, desempenho profissional e/ou empresarial, algumas das quais expostas no pequeno exemplo que dei ao iniciar este texto. Pois, afinal, não podemos nos convencer de que um dado vocabulário nos é dado de graça, voluntariamente, seja por força das "evidências empíricas" (a economia, o mercado, o psiquismo etc.), seja por pressão da "naturalidade" do "mundo". É preciso avançar em direção a um tipo de genealogia de alguns termos que empregamos e que tratamos como peças naturais depositadas numa espécie de museu em nossa mente.

É por esse viés que pretendo abordar o que se poderia aqui denominar como sendo o vocabulário das habilidades e da competência. Penso eu que devemos analisar as conexões existentes na malha de crenças que constitui esse vocabulário como articuladas em torno de uma série de normas e regras que prescrevem e orientam um determinado constructo semântico onde, aí sim, termos ganham sentido e existência, de modo a configurarem um complexo de práticas discursivas aprovadas e aceitas. Tal complexo pode ter como aspectos nucleares as seguintes crenças:

a idéia de ação individual;

a idéia de personalidade;

a idéia de performance;

a idéia de learning society. 
Em meu modo de ver a questão, e que será detalhado em seguida, essas quatro crenças poderiam estar na base de formação e plausibilidade do vocabulário das habilidades e da competência, pois para que este pudesse ser formado ele teria de associar-se a outras crenças tidas, elas também, por verdadeiras. A coerência desse vocabulário e, mais ainda, seu caráter de necessidade ou naturalidade (intuitivamente extraídos de mensagens como a que citei no início), advém de sua reificação no quadro de descrições, justificativas e razões que identificam o jogo de linguagem do trabalho nas chamadas sociedades pós-industriais, nas sociedades em que passa a predominar a flexibilidade dos mercados e da economia, enfim, nas sociedades orientadas pelo viés neoliberal. Esse último ponto poderia levantar uma objeção, afinal, a flexibilização do trabalho e dos mercados, o viés neoliberal e a caracterização de uma sociedade pós-industrial, não são termos isolados, desligados daquele jogo de linguagem que deu origem ao vocabulário das habilidades e da competência (ambos agindo um sobre o outro). Este último não teria a força que tem exceto se atendesse a certos propósitos, e não seria absurdo dizer que tais propósitos são, entre muitos outros, os seguintes:

incrementar a produtividade do trabalho, ou seja, qualificar pessoas para desempenharem várias funções ao mesmo tempo, arcando com várias competências.

fazer o indivíduo gerir responsabilidades privadas pela condução de sua própria vida profissional. Isso implica no seguinte: o indivíduo tem de bancar os custos de sua formação profissional; ele tem de avaliar-se periodicamente para ver se está adequado às regras e exigências que o mercado demanda dele.

desmantelar a confiança, tanto em ações tomadas em conjunto, visando a interesses públicos, quanto na ação e eficácia do Estado para gerir dificuldades ou conflitos na sociedade.

já que as empresas não têm mais condições de garantir o pleno emprego, elas procuram incentivar os indivíduos a manter sua empregabilidade para o mercado e, assim fazendo, elas próprias estão suscetíveis de contratar pessoas com maior nível de habilidades. Visase, aqui, à desregulamentação do trabalho e dos direitos trabalhistas.

aumentar a concorrência das empresas, principalmente no que concerne à participação delas no mercado mundial: a variável qualidade de pessoas é muito importante para a eficiência e competitividade, principalmente num momento em que a produção de bens simbólicos é fundamental (propaganda, tecnologias de informação etc.).

criar, por um lado, um upskilling no mercado de trabalho, fazendo crescer rapidamente e se intensificar agressivamente o nível geral de formação técnico-profissional de carreiras sofisticadas e de ponta. Por outro lado, cria uma maior polarização entre carreiras, pois aquelas onde se exige (ainda) menor formação tendem a ter um achatamento nas suas faixas de rendimento.

Esses propósitos, escolhidos dentre uma variedade de elementos muito ampla, servem para nos alertar de que o aqui denominado vocabulário da competência e da habilidade não é meramente uma nominação, ou seja, a atribuição de um nome, pura e simplesmente, àquelas questões relativas ao trabalho, às empresas, ao mercado e mesmo ao Estado. Pelo contrário, ele é uma poderosa maneira de descrever como é que se articulam certos objetivos e propósitos, muitos deles ligados a questões de poder, força, violência física, dominação, exploração etc., com nossas crenças sobre quem devemos ser em matéria de trabalho e/ou desempenho profissional. A seguir vamos detalhar as quatro crenças acima apontadas, tentando ver seu papel vital nos discursos e formas de vida implicados na teia de crenças e de justificativas do vocabulário da habilidade profissional. 


\section{O vocabulário da habilidade e da competência}

Podemos fazer aqui um contraste. Primeiro, lembremos da época em que se podia falar em pleno emprego, isto é, em relações de trabalho marcadas por uma grande variedade de regulações e de garantias, seja da parte do empregador, seja da parte do empregado. Paralelo a isso, o Estado, que em países avançados era chamado de Estado de bem-estar social, também se intrometia como árbitro nas relações de trabalho, policiando e amparando o "mais fraco", no caso o trabalhador, das investidas exageradas do capital. A sociedade era organizada em classes sociais, de modo que uma rígida linha divisória era feita, aqui e ali, para apartar setores distintos da participação social e econômica. Nesse tipo de sociedade, que alguns chamam de sociedade de classes, a aquisição de uma identidade social era feita mediante signos de pertencimento de classe, tais como as heranças e o lugar que o status garantia, por tradição, aos indivíduos (Ehrenberg, 1991; 1995; 1998).

$\mathrm{Na}$ outra ponta do contraste, tomemos as sociedades contemporâneas. Há um discurso que diz mais ou menos o seguinte: hoje as narrativas de classe já não mais conseguem garantir uma identidade social. Agora, num cenário esvaziado de sinais dados a priori, o indivíduo é levado a se redescrever constantemente, com o intuito de se assegurar do que é digno, em certos momentos, de integrar a imagem de seu eu. Nas esferas política, econômica e social, uma série de transformações foi minando o chamado pleno emprego, e agora há uma necessidade constante de provar a própria performance para se ter empregabilidade, ou seja, estar pronto e disponível para a ciranda: perder-emprego-ganharemprego-procurar-emprego-oferecer-emprego etc. A palavra de ordem de hoje é: tenha um projeto e seja o empresário da sua própria vida, pois se você não se cuidar, dificilmente alguém o fará por você! (Ehrenberg, 1991; 1995; 1998).

Resumindo: graças à contínua reestruturação das relações sociais hoje assistimos a um enfraquecimento da ação do Estado (e de órgãos de representação de classe, como os sindicatos) no âmbito das relações entre empregador-empregado; a um esgotamento de modelos de condutas pessoais, as quais agora têm à disposição uma grande variedade de linguagens com as quais podem lidar; a uma espécie de privatização moral das responsabilidades pela ação, quer seja no caso do trabalho (a idéia de projeto individual, de deal with yourself, de performance etc.), quer seja no caso das questões tratadas como públicas (ações coletivas, a política, órgãos e sistemas de representação etc.). Nesse contexto, há uma forte e vigorosa injunção no sentido de forçar o indivíduo a agir por conta própria. Veja-se alguns dos mais comuns e típicos discursos das empresas: há um incentivo muito grande para que seus funcionários sejam empreendedores, atualizados, enfim, há uma pressão para que adquiram permanente capacitação. Mas, no final das contas, o que ocorre é: o indivíduo está arcando com deveres que caberiam ser divididos pela empresa (por exemplo, custos de formação, embora possa se argumentar que as empresas gastam muito hoje em dia com esse tipo de coisa) e/ou pelo Estado (políticas de requalificação, de treinamento, de reinserção profissional etc.). Atualmente, se o indivíduo não age por conta própria ele é logo classificado como "acomodado", "sem iniciativa", "fracassado", entre tantas outras designações moralmente depreciativas.

Hoje, a "patologia do caráter" (Ehrenberg, 1998), por assim dizer, fica por conta da não-iniciativa do sujeito. Isto é, diante de todas as pressões e mandatos para ele agir por conta própria; diante da tarefa de ser o empreendedor racional e soberano de sua própria vida e carreira; diante da ausência quase completa (principalmente em países como o Brasil) de amparos e/ou garantias públicos do Estado ou de uma ação conjunta vigorosa; o sujeito não tem outra saída senão fazer prova de competência, seja ela de qual ordem for. Assim, ele está sendo continuamente treinado para adquirir um código de conduta que põe extremo relevo na ação individual, desvalorizando - ou tratando com menor importância - linguagens de 
implicação coletiva, visando a propósitos coletivos. Mas, é preciso acrescentar outra transformação semântica no antigo vocabulário do indivíduo que se deixava levar por normas e condutas fixadas para ele a priori (pelo Estado, pela empresa, pela família etc.). Será preciso entrar em cena a noção de personalidade.

A noção de personalidade comporta algumas premissas básicas. Primeiro, tal como foi descrita pela psicologia intimista (Sennett, 1989), pressupõe algo que a pessoa tenha e que possa ser isolado, protegido e cultivado num ambiente individual, privado, apartado do escrutínio do outro. Aqui podem ser ancoradas noções como "estrutura", "disposições individuais para certos comportamentos ou sentimentos", "self interior" etc. Na linguagem do dia-a-dia se diz, freqüentemente, que "fulano tem personalidade", ou seja, que tem alguns traços, talvez permanentes, capazes de o identificar e de o fazer reconhecido como sendo um "fulano tal e tal". Esse aspecto da personalidade a coloca como uma idiossincrasia que está separada do exterior e que tem seu mais amplo espectro de modificações na esfera privada.

Contudo, o aspecto que mais me interessa aqui é que a noção de personalidade é muitas vezes chamada em auxílio quando se trata de descrever as ações dos indivíduos (Sennett, 1989; 1999). Estas podem ser apresentadas como reflexo de uma intenção deliberada e própria de uma determinada personalidade. Como tal, tem de ser reconhecida em sua pura idiossincrasia e valores próprios. É por isso que o discurso que prioriza a tomada da ação individual pôde ser reconhecido como legítimo e plausível: porque já havia sido sedimentada uma noção de que o ser humano tem características próprias, privadas, capazes de discernir sobre o que é melhor para si e para seus sentimentos, e que somente uma atitude tomada nesse ambiente protegido e seguro, que é o interior de si mesmo, poderia ser reconhecida como legítima para o indivíduo, visto que espelharia sua "verdadeira" personalidade. Portanto, falar em ação individual é perfeitamente inteligível num tipo de sociedade em que a forma privilegiada de subjetivação é a individualista, com assento na noção de personalidade.

Das duas crenças anteriores, ou seja, da crença na ação individual e na personalidade, se configura um campo de possibilidades para uma conversão de códigos sociais de condutas baseados na política do Estado de bem-estar social (ou seja, em políticas que agiam e falavam em nome dos indivíduos e por eles), para uma política de indivíduos, cujo expoente é a máxima valorização das ações pessoais, no trabalho, no lazer e em todos os outros campos da vida. Agora, as duas outras crenças seguem para dar forma final a esse quadro que estou tentando construir.

Vejamos, primeiro, a crença na performance (Ehrenberg, 1991). Esta crença diz mais ou menos o seguinte: agir por si mesmo; ser o empresário da própria vida; importar-se prioritariamente com o desabrochar da sua própria personalidade ou com a dos seus amigos e pessoas próximas; não esperar que o Estado ou a "sociedade" faça alguma coisa por você; não confiar demais no seu emprego, mas sim na sua própria capacidade de ser empregável; levar a cabo a tarefa de sempre aprender e de sempre aprimorar suas capacidades e competências para não ser passado para trás (e tantas outras idéias que fazem parte do vocabulário da habilidade e competência). Tudo isso é importante para você; mas, deve fazer isso tendo em vista um valor importante: a performance. Ou seja, todas essas atividades em nome de si mesmo, em nome de seu próprio valor, devem ser feitas tendo por parâmetro a performance de sua ação (Ehrenberg, 1991; 1995; 1998). Essa crença implica numa idéia de permanente improvement na ação individual, pressupondo que as competências dos indivíduos são sempre adquiríveis e remodeláveis. Mas, a performance é também um item de avaliação e de atribuição de qualificativos. Buscar o desempenho da performance é ser sensível à necessidade tornada plausível pela última das crenças que vamos descrever: a learning society (Legge, 1995).

Learning society é usada aqui num sentido deliberadamente restritivo. $\mathrm{O}$ que ele significa? Significa um conjunto de discursos, principalmente no que tange ao mercado de 
trabalho, que destaca o fato da necessidade contínua de aprender e de conhecer. É afirmado que o mundo está em constante transformação, que estamos atravessando uma época de mudanças de paradigmas e que precisamos estar a par de tudo isso; é dito que a globalização nos força a interagir com muitas culturas e tendências; que os processos de produção têm cada vez mais uma carga de reflexividade demandando ser apreendida para melhor execução; é dito que o "conhecimento" é a chave para todas as coisas e que, quem não o tiver, vai ser deixado de fora na grande ciranda que é o mercado mundial. É aqui que o vocabulário da competência entra.

Ter competência, numa sociedade que prioriza o learning, passa a ser fundamental: como o nível de refinamento técnico/científico do mercado, principalmente em áreas estratégicas ou de ponta, elevou-se de maneira considerável, ter uma habilidade significa deter uma ferramenta ou uma chave de acesso. Assim, pessoas que falham em termos de produtividade, por conta de seu descompasso diante do ideal da learning society, têm seus rendimentos severamente restringidos, tendo como saída a imposição quase natural para adquirir educação a fim de sair do sufoco em que se encontram. Mas, na prática, não parece ser provável que um aumento no nível de educação irá trazer a garantia de um equilíbrio na oferta e na procura de empregos, pela simples razão de que o nível de qualificação está cada vez mais alto e a seleção tornando-se bem mais recrudescida, por conta de um movimento linear de upskilling da sociedade como um todo (Legge, 1995). Uma das conseqüências, já apontadas, é a ampliação na faixa de rendimento entre trabalhadores de alta performance e trabalhadores mais abaixo no regime da competência.

Mas, do ponto de vista que nos interessa, a plausibilidade do discurso da competência e da aquisição de conhecimentos se encontra aqui: se as pessoas são instruídas a encontrarem por si mesmas, por meio de suas próprias personalidades, seu lugar na economia ou no mercado de trabalho, sem o suporte do Estado, então elas são também incentivadas a tomarem todas as medidas necessárias para sua "educação", alijando o Estado de ter de investir recursos nesse sentido (quem hoje esperaria do Estado uma iniciativa para incrementar a própria profissão? Isso, sob diversos pontos de vista, e sob diversas justificativas, está completamente fora de questão!). O discurso da competência, portanto, tem uma finalidade prática difícil de ser negada. Entretanto, é também importante destacar que o termo "educação", aqui, aproxima-se mais de um conjunto de habilidades que devem ser adquiridas face àquilo exigido no mercado de trabalho, seja em quaisquer de suas inscrições. Portanto, num certo sentido interpretativo, learning society é um termo que ironiza o fato de que a aprendizagem, nesse tipo de sociedade é, muito comumente, orientada para a aquisição stricto sensu de conhecimentos de mercado.

Os objetivos da learning society são, portanto, simples e claros (Legge, 1995): para os indivíduos se tratam destes: consigam se educar até o nível mais alto que puderem. Para as empresas: trabalhem para incrementar a base de conhecimentos de suas atividades com o intuito de manterem-se à frente da competição. Finalmente, para os governos: incrementem a qualidade da educação oferecida e se certifique de que o mais alto número de pessoas de sua população se engaje nela, pois assim se conseguirá manter os níveis de desemprego baixos (e de empregabilidade altos).

As empresas, respondendo às solicitações que lhes são feitas, criam sistemáticas de ensino que priorizam o contato com as questões/problemas que as atingem de modo particular. Não é raro, hoje em dia, notar que existem empresas que têm sua própria universidade corporativa, e nos quadros curriculares também não deve ser difícil de encontrar a idéia de que o vocabulário da habilidade e da competência depende: a) das condições pessoais (motivação, engajamento, comprometimento, auto-estima, etc.) dos indivíduos em aprender - sua personalidade; b) de uma conscientização acerca da necessidade de agir individualmente, embora agir individualmente em equipe; c) da capacidade de solucionar problemas que atingem o cotidiano do contexto de trabalho, numa empresa em particular, 
numa situação em particular etc.; d) da conscientização de que sem conhecimento, sem habilidades e sem um "diferencial" não se estará habilitado para ser reconhecido como um sujeito de performance. É na articulação destes itens que se pode, então, ver consolidado o núcleo do discurso ou vocabulário da habilidade e da competência. Deste ponto à questão da subjetividade não há grande distância, e é com isto que as considerações finais deste texto irão se ocupar.

\title{
O vocabulário da habilidade e da competência e a subjetividade
}

O vocabulário da habilidade e da competência é parte indissociável e necessária de uma época que impõe, a todos sem exceção, a grande tarefa, seja no trabalho, seja na vida pessoal, enfim, em amplos setores da existência, de formar a própria individualidade, construir um sentido pessoal para a existência. A carreira profissional, por sua vez, funciona como um canal viável e promissor para a construção de uma identidade pessoal cujo principal parâmetro é a excelência e a competitividade com os outros. Para ilustrar esse novo cenário de florescimento e germinação do vocabulário da habilidade, antes referido, transcrevo uma passagem muito interessante do trabalho de Ehrenberg (1998):

\begin{abstract}
A convergência do estatal, do profissional, do escolar e do privado sobre a iniciativa pessoal, combinada a uma liberdade de modos inédita e a uma multiplicação da oferta de referências, dá ao psíquico uma inscrição social e, portanto, pessoal, totalmente inédita. O estilo de resposta aos novos problemas da pessoa toma a forma dos acompanhamentos de indivíduos, eventualmente sobre a duração de uma vida toda. Eles constituem uma manutenção que se desenrola por múltiplas vias, farmacológicas, psicoterapêuticas ou sócio-políticas. Produtos, pessoas ou organizações são o suporte disso. Esses atores múltiplos, estando na dependência das atuações dos serviços públicos ou dos serviços relacionais privados, referem-se a uma mesma regra: produzir uma individualidade suscetível de agir por ela mesma e de se modificar apoiado-se sobre seus recursos internos. Essa regra pode servir tanto como instrumento de dominação quanto como meio de reinserção ou de responsabilização terapêutica. Os afrontamentos, as estratégias ou os julgamentos dos atores se constróem nesse imaginário e não naquele de uma 'luta final' ou de uma assistência para a vida. Penetrada em nossos usos, inserida em nossos modos, dispondo de um vocabulário empregado permanentemente (elaborar projetos, passar contratos, suscitar a motivação etc.), esta regra forma conosco uma só coisa. Ela se instituiu. Essas novas formas comuns de produção da individualidade são as instituições de si. (p. 244)
\end{abstract}

Nesta passagem é possível notar a emergência de um tipo de subjetividade que é instada a se preocupar com sua contínua performance, visto que modelos instituídos (coletivamente, grupalmente etc.) de conduta ou ação, já não desfrutam de uma ampla credibilidade. Paradoxalmente, essa nova figura da individualidade cria a demanda por assistência, por amparo e por mecanismos de ajuda. Como diz Ehrenberg (1995), o indivíduo é, hoje, uma autonomia assistida de múltiplas formas. O próprio vocabulário da competência requer a proliferação desses dispositivos de ajuda, os quais passam então a funcionar como mecanismos de "usinagem interna" (Ehrenberg, 1998) para o próprio indivíduo. Nesse sentido, basta lembrar do incontável número de publicações destinadas a incrementar a performance individual, sem dizer dos infindáveis tipos de terapias, auto-ajudas, exercícios, regimes, entre tantos outros.

Antes de concluir este texto é preciso fazer uma importante observação. Em primeiro lugar, subjetividade, como a entendemos, é um efeito de linguagem. Ou seja, só se pode falar 
que "subjetividade" é isso ou aquilo lançando mão de uma teoria de verdade que diz, baseando-se em pressupostos valorativos (éticos/morais), o que deve contar como referente do que se está chamando como subjetivo. Nesse sentido, subjetividades diversas são produzidas, mantidas e extintas como função da troca, aperfeiçoamento ou abandono completo de determinados vocabulários, isto é, linguagens, formas de vida, discursos etc. $\mathrm{O}$ sujeito, portanto, é uma rede lingüística sem apoios transcendentes capazes de informar, ou de fixar invariavelmente, sua essência final. Do ponto de vista do sujeito, é irrelevante considerar os aspectos não lingüísticos do mundo como "determinantes" da subjetividade: pelo contrário, o sujeito tem de ser descrito em termos intencionais, com ação performativa sobre suas ações e crenças. Como diz Costa (1995), o sujeito é uma realidade lingüística, e o que altera essa realidade são "seres verbais ou figuras de discurso que podem ter, como de fato têm, uma enorme força performativa na definição das subjetividades humanas" (p. 43). Mais à frente o mesmo autor diz: "O sujeito é um tecido de quadros lingüísticos coerentes que são causas ou razões, conscientes ou inconscientes, de nossas ações ou estados psíquicos" (p. 44).

No meu modo de ver, essa descrição do sujeito como realidade lingüística é poderosíssima para nossa tarefa de entender como está sendo produzida a subjetividade em nossa época, principalmente quando tomamos a questão do trabalho (e de alguns dos vocabulários que tratam da questão). Assim, a título de perspectivas futuras, seria interessante e promissor ao campo psi que: a) questionemos a idéia de que "realidades" não lingüísticas, ou "concretas", tais como o "mercado" ou a "economia" etc. determinam, de modo inexorável, nossos modos de ser sujeitos; b) façamos uma espécie de "genealogia" para procurar entender a origem e fonte de manutenção do vocabulário da habilidade e da competência, tal como o descrevi acima - vocabulário que já está tão impregnado em nossos modos, tão disseminado no horizonte da cultura, que tendemos a pensar que seja algo natural, algo além da própria linguagem; c) é preciso, também, estarmos conscientes de que uma análise assim realizada não se apresenta como um ponto definitivo e inquestionável sobre o assunto em debate, capaz, por si só, de pôr por terra o vocabulário da habilidade e da competência (caso isso, por quaisquer razões que se possa oferecer, seja eleito como meta), alegando, por exemplo, que ele é incoerente com o restante das crenças culturais, aceitas, elas também, como verdadeiras. Certamente esta última alternativa não seria nenhum pouco persuasiva, nem tampouco eficaz. Seria o mesmo que dizer, mutatis mutantis, que a Inquisição, na Idade Média, era incoerente com as demais crenças verdadeiras que partilhavam as pessoas daquela época (visão teocêntrica do mundo, predomínio do poder institucional da Igreja etc.).

Por outro lado, esse reconhecimento não significa um pessimismo aterrador, semelhante ao que diz que nada podemos fazer. A consciência de que os vocabulários são contingentes, embora vigorosamente assimilados, nos permite pensar que, tal como a Igreja (ou o pensamento religioso em geral) perdeu um dia sua influência devastadora sobre nós, assim também o vocabulário da habilidade e da competência poderá perder a aderência quase que asfixiante que tem hoje (caso isso seja, de fato, posto em questão). Ora, o que poderia incentivar tal perda de aderência? Certamente não a Verdade, nem a chamada Ciência, nem uma "força" ou "entidade" superiores a nós; tampouco uma reconversão cultural em massa, atingindo a todos, de cima em baixo, à luz de um decreto (técnico-científico ou político, por exemplo). Acredito que uma mudança de vocabulários e, portanto, uma mudança nas imagens dos sujeitos, é possível por um longo trabalho de redescrições constantes, de novas tentativas para descrever o que é ser um sujeito, seja no trabalho, em casa, na vida privada etc. Perguntas quase românticas como Em que tem nos ajudado descrever o sujeito como alguém que deve estar preocupado com sua performance, com o grau de conhecimento que detém, com a possibilidade constante de ser deixado para trás? Essa imagem de sujeito tem servido para atrair um maior sentimento democrático - sentimento que o Ocidente tem desenvolvido e eleito como meta utópica para suas ações coletivas? Ou ele tem separado as pessoas, dificultado a convivência de alguma forma? Para mudar um vocabulário, para alterar 
seus aspectos conflitivos ou aqueles que estão em desavença com o restante das crenças culturais tidas por verdadeiras, é preciso um exercício de avaliação de prós e contras. Fora disso, é contar com a Providência Divina, com as Forças do Além ou com qualquer obra do Acaso (ou, o que é pior, contar com algum devaneio cientificista).

Concluo este texto com uma citação de Rorty (1995), quando ele, referindo-se à situação do pragmático diante da mudança cultural de vocabulários sobre o sujeito, diz (no caso, ele está se referindo à possibilidade de abandonar o vocabulário do que ele chama de "ativismo metafísico", ou seja, justamente aquele vocabulário que acredita que a "verdade" tem propriedades especiais, propriedades capazes de "espelhar", acuradamente, a "real natureza" das coisas):

Os pragmáticos estão na mesma situação dos ateus em culturas que são completamente dominadas pela religião. Tais pessoas só podem esperar traçar os contornos do que Shelley chama de "as gigantescas sombras que o futuro lança sobre o presente". Eles antevêem uma época em que as noções de Desejo Divino e Comando Cognitivo tenham sido, por razões similares, substituídas pela de Um Livre Consenso entre Investigadores. Mas, enquanto isso, o pragmático que insiste para que nossa cultura abandone o ativismo metafísico não pode argumentar que tal ativismo é inconsistente com a massa de nossas outras crenças, não mais do que um antigo ateísta Grego podia dizer que o sacrifício aos deuses olímpicos era inconsistente com a massa das outras crenças gregas. Tudo o que o pragmático pode fazer é o tipo de coisa que eles fizeram: apontar para a aparente futilidade da atividade metafísica, da mesma forma que apontaram para a aparente futilidade da atividade religiosa. (p. 300)

No cômputo dos prós e dos contras, cabe-nos a pergunta: vale a pena, compensa, é interessante tratar o vocabulário da habilidade e da competência, e o tipo de indivíduo que lhe corresponde (um indivíduo conquistador, excitado pela ascensão pessoal e pelo sucesso, cuja meta é a conquista de um lugar de reconhecimento feito por si mesmo), como algo "natural", "indispensável" e "verdadeiro"? A resposta será "sim" caso optarmos pela manutenção do estado de coisas em que nos encontramos: o tipo de crença de que só os melhores vencem na vida! A resposta poderá ser um "não" caso comecemos a olhar para outras possibilidades de subjetivação, outras formas de sermos sujeitos, outras maneiras de exercitarmos um sentimento democrático, onde, de fato, seja possível pensar num desenvolvimento pessoal e coletivo sem o sacrifício de uns em benefício de outros (em outras palavras: tornar o vocabulário da habilidade e da competência como outro vocabulário qualquer, num espectro amplo e plural de vocabulários que podem coexistir). $\mathrm{O}$ desafio, para quem quiser, puder e desejar, está lançado!

The ability and competence vocabulary: Some neopragmatic considerations

The aim of this paper is to present and discuss some of the main components of ability and competence vocabulary. Starting from a theoretical ransom of concepts comprised in the neopragmatic philosophy of language it is proposed that such vocabulary is characterized as a discursive structure articulated by the notion of personality, individual action, performance and by the notion of learning society, that is to say, by the idea of a society gone back to the continuous knowledge and learning. The paper still develops the argument that the ability and competence vocabulary institutes certain ways of life that, in function of its repetition and reiteration, begin to represent unquestionable and natural modalities of mechanisms of subjective formation, in a time in which the wide identity narratives lose their consistency, comprehending, among others, the loss of class and collective narratives - as they were articulated around the Welfare State policy - and the corrosion of work society (the end of the full employment).

Keywords: neopragmatism, work, subjectivity, discourse. 
Endereço para contato com o autor: pedrofernando@terra.com.br

Manuscrito recebido em: 01/09/2000

Aprovado para publicação em: 21/12/2000

\section{Referências}

Costa, J. F. (1992). A inocência e o vício. Rio de Janeiro: Relume Dumará.

Costa, J. F. (1994). Pragmática e processo analítico: Freud, Wittgenstein, Davidson, Rorty. In Jurandir Freire Costa (Org.), Redescrições da psicanálise (pp. 9-60). Rio de Janeiro: Relume Dumará.

Costa, J. F. (1995). A face e o verso. São Paulo: Escuta.

Costa, J. F. (1998). Sem fraude nem favor. Rio de Janeiro: Rocco.

Costa, J. F. (1999). Razões públicas, emoções privadas. Rio de Janeiro: Rocco.

Davidson, D. (1985). Inquiries into truth and interpretation. Oxford: Clarendon Press.

Ehrenberg, A. (1991). Le culte de la performance. Paris: Calmann-Lévy.

Ehrenberg, A. (1995). L'Individu incertain. Paris: Calmann-Lévy.

Ehrenberg, A. (1998). La fatigue d'être soi. Paris: Odile Jacob.

Ghiraldelli Jr., P. (1997). Para ler Richard Rorty e sua Filosofia da Educação. Filosofia, Sociedade e Educação, 1, 9-30.

Ghiraldelli Jr., P. (1998). Materialismo e subjetividade no projeto filosófico-pedagógico de Richard Rorty. In Margutti Pinto (Org.), Filosofia analítica, pragmatismo e ciência (pp. 323 331). Belo Horizonte: Humanitas.

Ghiraldelli Jr., P. (1999). Richard Rorty: A filosofia do novo mundo em busca de mundos novos. Petrópolis: Vozes.

Ghiraldelli Jr., P. (2000a). O que você precisa saber sobre didática e teorias educacionais. Rio de Janeiro: DP\&A.

Ghiraldelli Jr., P. (2000b). O que você precisa saber sobre filosofia da educação. Rio de Janeiro: DP\&A.

Legge, K. (1995). Human resources management. London: Macmillian.

Rorty, R. (1979). Philosophy and the mirror of nature. Princeton: Princeton University Press.

Rorty, R. (1991). Objectivity, relativism, and truth. Cambridge: Cambridge University Press.

Rorty, R. (1995). Is Truth a Goal of Inquiry? Davidson versus Wright. The Philosophical Quarterly, 45 (180), 282-300.

Rorty, R. (1999). Philosophy and social hope. Londres: Penguim Books. 
Sennett, R. (1989). O declínio do homem público. São Paulo: Companhia das Letras.

Sennett, R. (1999). A corrosão do caráter. Rio de Janeiro: Record. 